CONF-821111-25

GA TeGhm@|gIIes GA-A16913

\title{
DESIGN OF A DEE VACUUM VESSEL FOR DOUBLET III
}

\author{
by \\ L. G. DAVIS
}

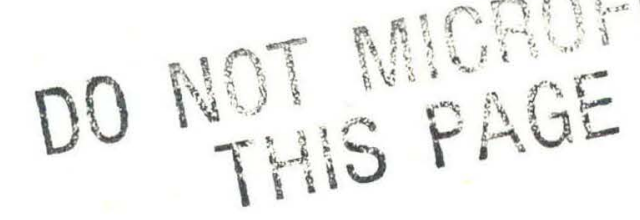




\section{DISCLAIMER}

This report was prepared as an account of work sponsored by an agency of the United States Government. Neither the United States Government nor any agency Thereof, nor any of their employees, makes any warranty, express or implied, or assumes any legal liability or responsibility for the accuracy, completeness, or usefulness of any information, apparatus, product, or process disclosed, or represents that its use would not infringe privately owned rights. Reference herein to any specific commercial product, process, or service by trade name, trademark, manufacturer, or otherwise does not necessarily constitute or imply its endorsement, recommendation, or favoring by the United States Government or any agency thereof. The views and opinions of authors expressed herein do not necessarily state or reflect those of the United States Government or any agency thereof. 


\section{DISCLAIMER}

Portions of this document may be illegible in electronic image products. Images are produced from the best available original document. 
This report was prepared as an account of work sponsored by an agency of the United States Government. Neither the United States Government nor any agency thereof, nor any of their employees, makes any warranty, express or implied, or assumes any legal liability or responsibility for the accuracy, completeness, or usefulness of any information, apparatus, product, or process disclosed, or represents that its use would not infringe privately owned rights. Reference herein to any specific commercial product, process, or service by trade name, trademark, manufacturer, or otherwise, does not necessarily constitute or imply its endorsement, recommendation, or favoring by the United States Government or any agency thereof. The views and opinions of authors expressed herein do not necessarily state or reflect those of the United States Government or any agency thereof. 


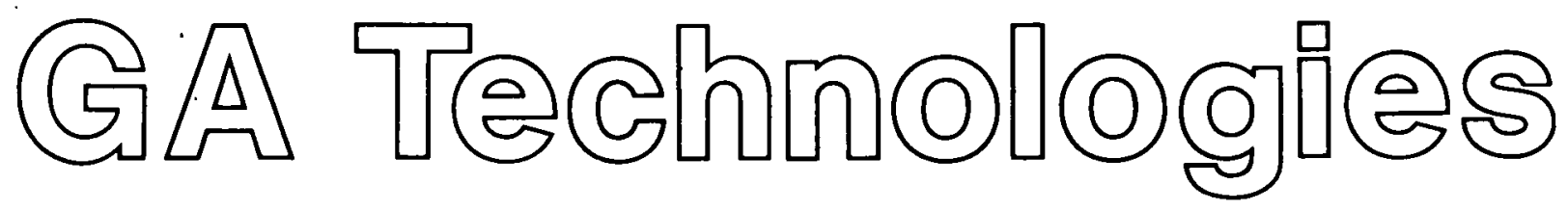

GA-A16913

\section{DESIGN OF A DEE VACUUM VESSEL FOR DOUBLET III}

This is a preprint of a paper to be presented at the 29th National Symposium of the American Vacuum Society, November 15-19, 1982 in Baltimore, Maryland.

GA-A--16913

by
L. G. DAVIS

DE83 017510

Work supported by Department of Energy Contract DE-AT03-76ET51011 


\section{DISCLAIMER}

This report was prepared as an account of work sponsored by an agency of the United States Government. Neither the United States Government nor any agency thereof, nor any of their employees, makes any warranty, express or implied, or assumes any legal liability or responsibility for the accuracy, completeness, or usefulness of any information, apparatus, product, or process disclosed, or represents that its use would not infringe privately owned rights. Reference herein to any specific commercial product, process, or service by trade name, trademark, manufacturer, or otherwise does not necessarily constitute or imply its endorsement, recommendation, or favoring by the United States Government or any agency thereof. The views and opinions of authors expressed herein do not necessarily state or reflect those of the United States Government or any agency thereof. 


\section{DESIGN OF A DEE VACUUM VESSEL FOR DOUBLET III* \\ Larry G. Davis \\ GA Technologies, Inc. \\ P.O. Box 81608 , San Diego, CA 92138}

\section{Introduction}

Doublet III is a large tokamak (by present experiment standards) built and operated since 1978 by General Atomic. Company for the U.S. Department of Energy and has a primary goal of investigating non-circular cross section plasmas. The research program is in its second year of neutral beam plasma heating experiments.

Operation of the device has demonstrated the ability to produce stable plasmas of reactor regime densities in a variety of plasma shapes, including doublets, as well as circles, dees and divertor configurations in the upper lobe of the indented vacuum vessel. Recent experiments which have concentrated on beam heating of plasmas in the upper lobe have demonstrated the importance of plasma current and cross section elongation in obtaining high beta (the ratio of plasma pressure to magnetic field pressure), a key parameter in the economics of generating power from tokamaks.

In the latter part of 1984, Doublet III will be shut down to replace the present doublet vacuum vessel with a new, larger vessel with a dee-shaped cross section, increasing the plasma volume by almost a factor of three. The new configuration, termed Big Dee, will embody the flexibility and performance capabilities essential for realistic modelling of presently envisioned tokamak

\footnotetext{
${ }^{*}$ Research supported by the United States Department of Energy Contract DE-AT03-76ET51011.
} 
reactor operating scenarios. The flexibility arises by virtue of a large increase in torus access while retaining much of the freedom in plasma shaping. Examples of planned experiments growing out of such flexibility are the comparison of pumped limiters and poloidal divertors and the optimization of plasma elongation and triangularity. The prediction of high performance is owed to a combination of the magnetic geometry, which has been chosen to maximize theoretical projections for $\beta$, and very large plasma current, which leads to the expectation of excellent confinement. In fact, the design value of the plasma current, which appears to be the single most important determinant of performance potential, is 5 MA, a value unrivalled by any other U.S. tokamak.

The Big Dee modification project has completed the basic physics design and conceptual engineering design phase and is beginning detailed engineering. The project is funded in FY83 for completing most of the detalled design and placing orders for long lead components and systems. This paper summarizes the conceptual engineering design, especially of the vessel itself.

Doublet III Capability

Doublet III was originally designed with an upgradable capability. The toroidal field coils are capable of $4.0 \mathrm{~T}$ (on present vessel axis) operation in an ohmic heating flux swing of $10.5 \mathrm{~V}-\mathrm{s}$. The poloidal field coils were likewise designed and built for the full flux swing. Present power equipment and toroidal coil prestress components have limited operation to $2.6 \mathrm{~T}$ and $5 \mathrm{~V}$-s. The present doublet-shaped vessel was designed to 
withstand $0.1 \mathrm{~ms}$ disruptions of $5 \mathrm{MA}$ plasmas. With the present volt-seconds and power equipment plasma currents as high as 2.2 MA in doublet plasmas and 1.1 MA in dees have been achieved.

Two, dual-source, neutral beam injectors each rated at $3.6 \mathrm{MW}$ of plasma heating power at $80 \mathrm{keV}$ are presently in operation on Doublet III. To date over 5 MW of power have been successfully injected and volume averaged betas of as high as $4.6 \%$ have been achieved.[1] In 1983 a third neutral beam, from a Doublet III U.S.-Japan cooperative upgrade program, will be added and bring beam heating capability to approximately $10 \mathrm{MW}$. Other upgrade hardware to be in place in 1983 will provide 1.5 MA operation. Also, a second motor generator is scheduled for acceptance tests in late 1982 .

After over a year of operation with three neutral beams into small dees, Doublet III will be shutdown and disassembled for installation of the new, large dee vessel (see Fig. 1) and a fourth neutral beam injector.

\section{Long-Term Direction}

In the presently conceived U.S. fusion program plan Doublet III in its Big Dee configuration and TFTR will be the two principal tokamak research facilities of the late 80 's. The design and capabilities of Big Dee are complementary to TFTR; i.e., high beta, elongated, moderate field in hydrogen for D-III; and moderate beta, circular, high field using D-T for TFTR. 


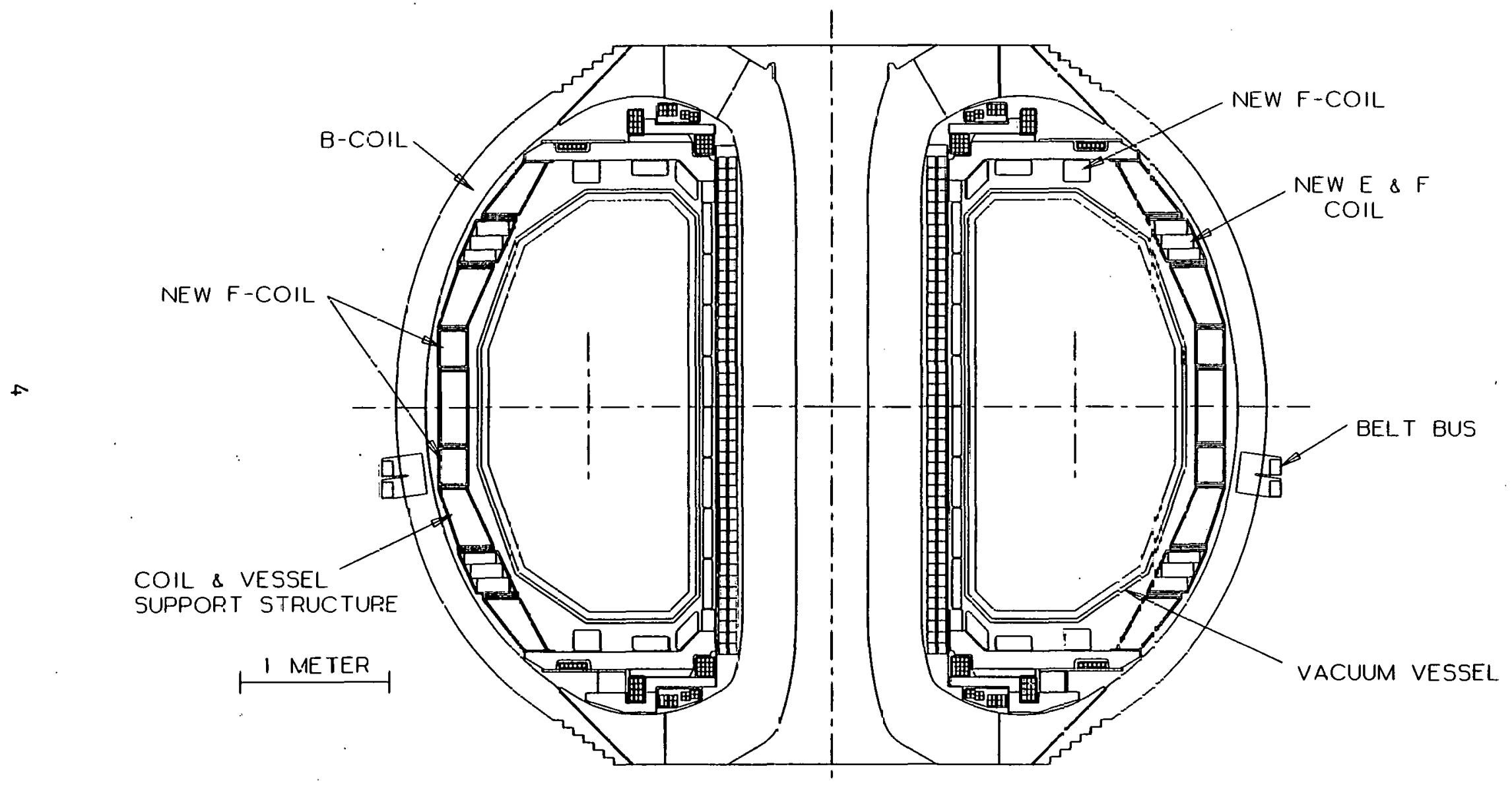

Fig. 1. Big Dee cross-section 
Big Dee will start up with 14 MW of neutral beams, 2 MW of electron cyclotron heating (ECH), and plasma currents of $2.5 \mathrm{MA}$ or more. A phased development of ion cyclotron range of frequencies (ICRF) heating is also planned (not funded at this time) such that approximately 5 MW of ICRF could be available at startup. The ultimate capabilities of the components will accommodate plasma currents to $5 \mathrm{MA}$ and an ohmic heating flux swing of $10.5 \mathrm{~V}-\mathrm{s}$. Components will also accommodate or be upgradable to implement long pulse (10 second), 20 MW rf heating. A summary of device parameters at present (including near term upgrades), at Big Dee startup and at ultimate capability is shown in Table 1 .

\section{Big Dee Project Plan}

The Big Dee Project consists of six major tasks, grouped by components or systems as follows:

1. Vessel

2. Coils

3. Support structure

4. Vessel protection

5. Power systems

6. Systems modifications

While this paper deals primarily with the design of the vessel, it includes design criteria of other interrelated systems. A brief statement of work for each system follows. 
TABLE 1

DOUBLET III - BIG DEE

DESIGN PARAMETERS

\begin{tabular}{|c|c|c|c|}
\hline & $\begin{array}{l}\text { Present ( } 1) \\
\text { (Doublet } \\
\text { Vessel) } \\
\end{array}$ & $\begin{array}{l}\text { Big Dee } \\
\text { Initial }\end{array}$ & $\begin{array}{l}\text { Big Dee } \\
\text { Ultimate } \\
\end{array}$ \\
\hline Major radius & $1.43 \mathrm{~m}$ & $1.67 \mathrm{~m}$ & $1.67 \mathrm{~m}$ \\
\hline Half width & $45 \mathrm{~cm}$ & $67 \mathrm{~cm}$ & $67 \mathrm{~cm}$ \\
\hline Elongation & 1.8 & 2.0 & 2.0 \\
\hline Aspect ratio & 3.2 & 2.5 & 2.5 \\
\hline Toroidal field on axis & 2.6. T & $2.2 \mathrm{~T}(2)$ & $2.2 \mathrm{~T}(3)$ \\
\hline Maximum plasma current & $1.5 \mathrm{MA}$ & $2.5-3.5 \mathrm{MA}(4)$ & $5.0 \mathrm{MA}$ \\
\hline Flux swing & $5.6 \mathrm{~V}-\mathrm{s}$ & $7.5 V-s(5)$ & $10.5 \mathrm{~V}-\mathrm{s}$ \\
\hline Generator stored energy & $3.0 \mathrm{GJ}$ & $3.0 \mathrm{GJ}$ & $3.0 \mathrm{GJ}$ \\
\hline $\begin{array}{l}\text { Neutral beam power } \\
\text { @ } 80 \mathrm{keV}\end{array}$ & $10 \mathrm{MW}$ & $14 \mathrm{MW}(5)$ & $14 \mathrm{MW}(6)$ \\
\hline ECH power @ $60 \mathrm{GHz}$ & $1 \mathrm{MW}$ & $2 \mathrm{MW}$ & 4-6 MW \\
\hline ICRF power & 0 & $5 \mathrm{MW}$ & $20 \mathrm{MW}$ \\
\hline $\begin{array}{l}\text { Discharge duration ( } 7) \\
\text { (current flattop) }\end{array}$ & $1.0 \mathrm{~s}$ & $1.5 \mathrm{~s}$ & $1.5 \mathrm{~s}$ \\
\hline
\end{tabular}

(1) Present values include planned upgrades through 1983.

(2) $2.6 \mathrm{~T}$ at $1.43 \mathrm{~m}$.

(3) Toroidal coil can operate at $3.4 \mathrm{~T}$ (on axis), but such an upgrade is not forseen.

(4) The Big Dee startup plasma current is a function of project funding.

(5) U.S. -Japan upgrade hardware.

(6) In a scenario of long pulse high power rf heating, the 0.5-1.0 second beams may or may not be used.

(7) Discharge durations are indicated for the maximum plasma current. Longer pulses at lower current and field are planned. Beam duration is limited to 0.5-1.0 second. RF heating heating will be capable of 5-10 second operation at full power. 
1. Vessel. The new vacuum vessel of dee-shaped cross section will be as large as allowed when locating poloidal field coils inside the existing toroidal coils. The vessel and other new components will be designed to preserve the full potential of the existing device components. Maximum possible vessel access will be provided for diagnostics and auxiliary heating. The vessel must withstand 5 MA plasma current disruptions as well as thermal loads implied by long pulse operation. Since long pulses at high power will come with advanced rf heating capability, the vessel can be upgradable, if necessary, with heat shields and/or cooling systems to handle the resulting heat loads and cool-down requirements.

2. Coils. Because the new vessel is larger in diameter than some existing poloidal field coils, such coils must be removed and replaced. The new coils must be suitable for $5 \mathrm{MA}, 1.5-$ second (flattop) operation and longer pulses at lower currents consistent with the ultimately available flux swing. Placement, number, and size of the coils must be optimized for current, cooling, resistance (power supply voltage), strength and torus access. In addition, coils not being replaced due to interference have been reviewed for consistent system capabilities. As a result, one pair of coils above and below the vessel will be replaced due to their relatively low water coolant cpacity.

3. Support Structure. A structure will be provided to support the vessel and poloidal field coils. It must withstand the magnetic coil loads and vessel fault loads yet maximize torus 
access. The adopted design concept consists of beams in a vertical plane inboard of alternate toroidal, field coils (Fig. 1). The system occupies no radial space beyond that required by the poloidal coils.

4. Vessel Protection. A system of limiters and armor will be provided to protect the vessel during normal operation and disruptions. Diverted configurations require additional special armor. The material for limiters and armor is dictated by thermal loading. Water-cooled, coated graphite tiles will be used in the areas with high power loading. Inconel will be used for disruption protection limiters. The design is an extension of the existing vessel armor and limiters. The initial Big Dee components will be upgraded for high power, long pulse operation. The primary limiters will be discrete and pumped.

5. Power Systems. Adequate power system components will be added for 2.5-3.5 MA operation for 1.5-seconds. Modular add-ons will raise the system capability to $10.5 \mathrm{~V}$-s ohmic flux and 5 MA (up to $4 \mathrm{MA}$ is possible with adequate power supplies at $7.5 \mathrm{~V}-\mathrm{s}$ ), and increase its long pulse performance.

6. Systems Modifications, Several main systems must be modified to successfully accommodate the design requirements. These include: Instrumentation and Control for longer pulse data acquisition and new component monitoring; Neutral Beams which must be moved and interfaced with the new vessel; and Diagnostics which must also be moved and modified. 
Vacuum Vessel Design

Efforts on the new vessel include four main tasks:

1. Vessel

2. Vacuum system

3. Vessel insulation

4. Vessel cooling

The following sections describe each area in more detail.

\section{Vesse1}

The objectives for the Big Dee vacuum vessel are to obtain: a base pressure of $2 \times 10^{-8}$ Torr or less; a toroidal resistance of $0.13 \mathrm{~m} \Omega$ or more; a maximum plasma volume; the capability of withstanding large impulsive magnetic loads; and the capability (with upgrading of the heat removal system) of withstanding 20 MW of heating for 10-second operation.

In order to meet the requirements delineated above, the vessel is an all welded chamber fabricated out of conical and cylindrical sections. The material used is Inconel 625 which has a tensile strength of approximately $830 \mathrm{MPa}(120 \mathrm{ksi})$ at $250^{\circ} \mathrm{C}$. The walls of the vessel are corrugated sandwich construction (see Fig. 2) with skin thicknesses of $2.36 \mathrm{~mm}$ (0.094 in.). The poloidally oriented corrugations, which are $1.59 \mathrm{~mm}(0.063 \mathrm{in.})$ thick, serve as passages for a cooling system and secondary vacuum.

The vessel has approximately 130 potential port or feedthrough locations between coils. The ports are designated for diagnostics, neutral beams, rf antennas, limiters, vacuum pumping, 


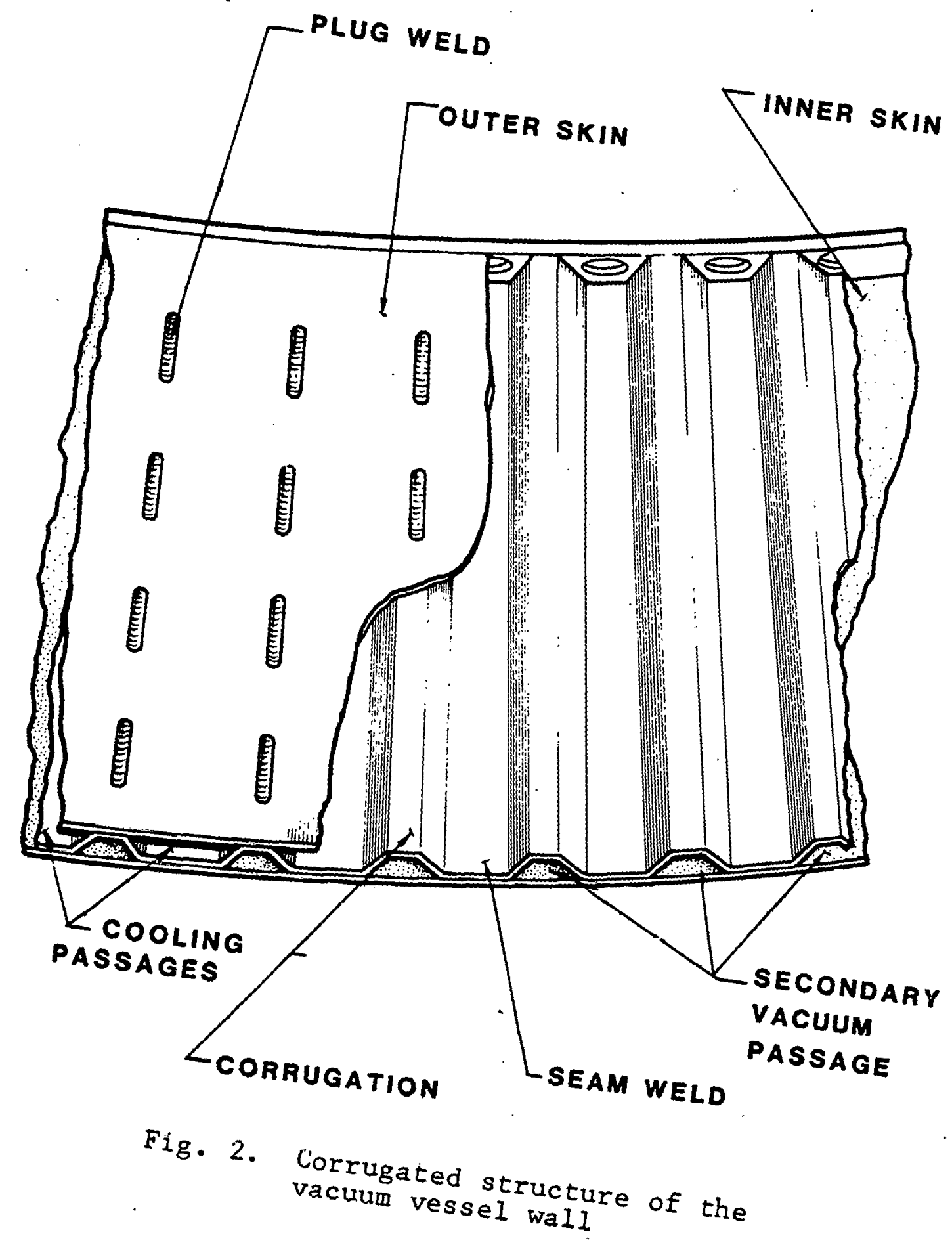


etc. The final number and configuration of the ports remain to be determined, but will depend on vessel stresses, neutral beam shinethrough, and structural interfaces. Most ports will be circular and have Conflat-type hard seals.

The vacuum vessel has an outer radius of $2.44 \mathrm{~m}$ (96.1 in.), a minimum radius of $0.91 \mathrm{~m}$ ( $36.0 \mathrm{in.})$, and a height of $2.87 \mathrm{~m}$ ( 115.0 in.), and is supported at the outer midplane in six places by guided supports held in place by the support structure.

The vessel design criteria and parameters are summarized in Tables 2 and 3 , respectively. The numbers in parentheses refer to the long pulse operating mode. While the present vessel changeout program does not include the long pulse upgrade, the new systems will be designed to handle the conditions that are expected to arise with long pulse operation.

The design of the vacuum vessel is similar to that of Doublet III.[2] The sandwich wall construction with minimum skin and wall thickness achieves high toroidal electrical resistance with maximum plasma volume. Inconel 625 material was chosen because it affords the desirable combination of high strength and high resistivity.

The detailed structural design of the vacuum vessel involves two major decisions: (1) choosing the skin thicknesses, and (2) choosing the spacing between the two skins. Skin thickness is set primarily by the membrane stresses produced at design loads. 
TABLE 2

BIG DEE VESSEL DESIGN CRITERIA*

Toroidal resistance

Plasma current disruption time

Internal pressure

Maximum leak rate

Maximum temperature - discharge cleaning

Nominal plasma power

Plasma Current

Pulse time - flattop

Cycle time

Plasma wall separation
$>0.13 \mathrm{~ms}$

$>1 \mathrm{~ms}$

$<2 \times 10^{-8}$ Torr

$5 \times 10^{-6}$ Torr $-\ell / \mathrm{sec}$

$250^{\circ} \mathrm{C}$

$20 \mathrm{MW}$

5 MA (3 MA)

$1.5 \mathrm{~s}(10.0 \mathrm{~s})$

$300 \mathrm{~s}(600 \mathrm{~s})$

$5-10 \mathrm{~cm}$

TABLE 3

BIG DEE VACUUM VESSEL PARAMETERS*

Inside height

$2.87 \mathrm{~m}$

Maximum radius

$2.44 \mathrm{~m}$

Minimum radius

$0.91 \mathrm{~m}$

Height-to-width ratio

1.91

Volume

$37 \mathrm{~m}^{3}$

Surface area

$77^{\circ} \mathrm{m}^{2}$

Cross section area

$3.7 \mathrm{~m}^{2}$

Wall thickness

$2.54 \mathrm{~cm}$

Inner wall skin thickness

$2.36 \mathrm{~mm}$

Outer wall skin thickness

$2.36 \mathrm{~mm}$

Corrugation thickness

$1.59 \mathrm{~mm}$

Material

Inconel 625

Coolant

Air (water)

Maximum average cooling system load

$100 \mathrm{~kW}(330 \mathrm{~kW})$

*Values in parentheses are for long pulse operation. 
These include the static atmospheric load as well as the dynamic magnetic load due to a plasma disruption. Minimum skin thickness is desirable in order to reduce magnetic error fields and magnetic loads. The distance between skins of the walls determines bending rigidity and is governed primarily by maximum allowable bending stresses and structural stability. The reference vessel design calls for $2.54 \mathrm{~cm}$ ( 1 in.) overall wall thickness everywhere. Both inside and outside skin thicknesses are $2.36 \mathrm{~mm}$ $(0.094$ in.) everywhere.

Material Selection. The choice of material and the specification of a minimum acceptable toroidal resistance are two coupled design decisions that are influenced by a number of elèctromagnetic, mechanical and thermal constraints. The existing vessel is made of Inconel 625, a high strength alloy containing more than $70 \%$ nickel. Its selection over other materials such as stainless steel was dictated by strength requirements based on a specific set of assumptions concerning the electromagnetic pulsed loads that accompany a plasma disruption. Experience gained from Doublet III and other large scale fusion devices has made it possible to relax these requirements, as shown in Table 4. The material properties of Inconel 625 are listed in Table 5.

An adequate prolonged voltage level of $100 \mathrm{~V}$, necessary for plasma breakdown and subsequent initial ohmic heating at low gas pressure levels, is achievable for a vessel resistance greater than $0.13 \mathrm{~m}$. The Big Dee vessel wall material thickness of $6 \mathrm{~mm}$ for Inconel corresponds to $0.2 \mathrm{~ms}$. 
TABLE 4

COMPARISON BETWEEN ASSUMPTIONS MADE IN DOUBLET III AND THE PRESENT DESIGN

$\begin{array}{lll}\text { Maximum plasma current } & \frac{\text { D-III }}{\text { Big Dee }} \\ \begin{array}{l}\text { Plasma disruption time } \\ \text { (1/e time for plasma current decay) }\end{array} & 5 \mathrm{MA} & 5 \mathrm{MA} \\ \text { Vacuum breakdown voltage } & 0.1 \mathrm{~ms} & 1 \mathrm{~ms} \\ \quad \text { Based on initiation with plasma pressure } & \text { High } & \text { Low } \\ \text { Maximum ohmic heating coil current } & 250 \mathrm{~V} & 220 \mathrm{kA}\end{array}$

TABLE 5

INCONEL 625 MATERIAL PROPERTIES AT $150^{\circ} \mathrm{C}$

Resistivity, $\Omega-c m$

Minimum yield strength, MPa (ksi)

Specific heat, $\mathrm{J} / \mathrm{g}-{ }^{\circ} \mathrm{C}\left(\mathrm{Btu} / 1 \mathrm{~b}-{ }^{\circ} \mathrm{F}\right)$

Elastic modulus, $\mathrm{GPa}$ (psi)

Density, $\mathrm{g} / \mathrm{cm}^{3}$ (lb./in. $\left.{ }^{3}\right)$
$131 \times 10^{-6}$

$414(60)$

$0.435(0.104)$

$200\left(27 \times 10^{6}\right)$

$8.4(0.305)$ 
The following sections discuss the most important considerations affecting vacuum vessel material and thickness.

Operating Space. [3] Because the parameters of a tokamak are so interrelated, it is prudent to establish a reasonable operating space in order to limit design criteria. While stable MHD equlibria with betas in excess of $10 \%$ have been predicted for Big Dee, operating above this value at full field does not seem necessary as beta limits can be evaluated at lower fields. Similarly, if reasonable limits are established for $q$, a measure of the helical twist of the field lines, and for ${ }^{B} p$, the ratio of plasma pressure over the square of the poloidal field, then a reasonable operating space based on device size and field capability can be defined. Such an operating space for Big Dee is shown in Fig. 3, where plasma current is given as a function of $B_{p}$, for $\langle\beta\rangle=10 \%$ and $B_{T}=2.1 \mathrm{~T}$. An engineering constraint of 5 MA maximum plasma current is included. Constraining the design along this curve of constant plasma pressure (constant $B$ and $\mathrm{B}_{\mathrm{T}}$ ) allows a design based on maximum plasma current to be adequate for the space under the curve. This is because several key engineering parameters, especially vessel pressure and field-shaping coil currents decrease at lower plasma current and higher $\beta_{p}$.

Design Loads. The two primary loadings on the vessel, static atmospheric pressure and magnetic loading produced when the plasma disrupts, act simultaneously. When the plasma disrupts following the onset of some instability, it loses its thermal energy in a time on the order of 0.1-1 ms while its current may decay over a 


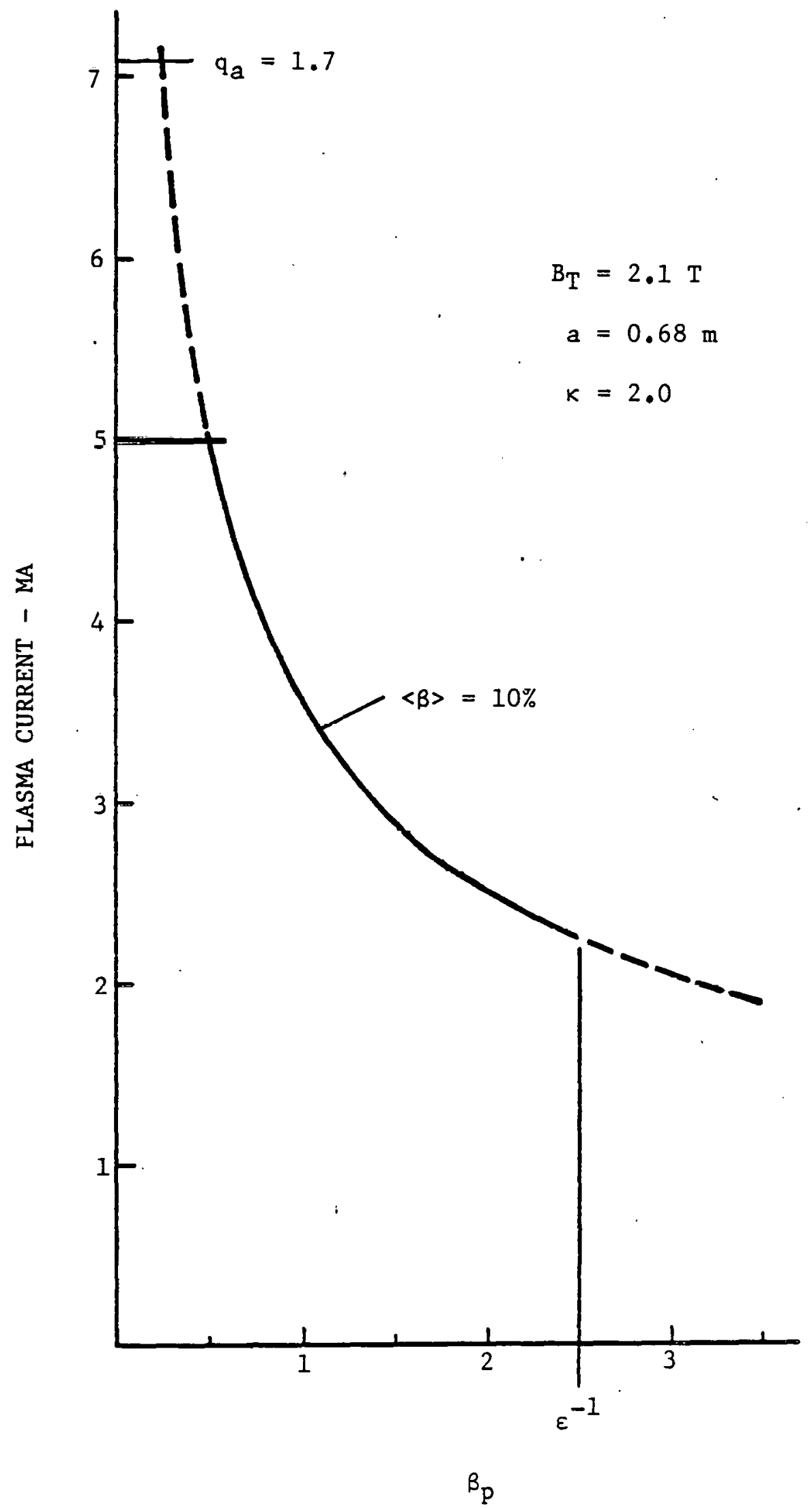

Fig. 3. Big Dee operating space 
considerably longer period. Current decay times on the order of 1 ms have been observed in low current tokamaks. In Doublet III, the decay time has generally been in excess of $5 \mathrm{~ms}$. For conceptual vessel design, however, a conservative assumption of a $1 \mathrm{~ms}$ plasma current decay was made. The plasma disruption loading then is conservatively based on a plasma current of $5 \mathrm{MA}$ (at $\beta_{p}=0.6$ ) which disrupts in 1 ms [note that the Experimental Test Reactor (ETR) has chosen $20 \mathrm{~ms}$ for its design basis].

The magnetic disruption load is impulsive in nature and acts to implode the vessel, i.e., it acts in the same direction as the atmospheric loading, but is not uniform, owing to varying poloidal field and vessel resistive effects. The resulting peak pressure on the vessel is 6.1 and 3.4 atmospheres on the inside and outside walls, respectively, and the intensity of the pressures varies with time. There are additional loads that the vessel and its supports must react, including dead weight, seismic, vessel misalignment with the toroidal field, and a fault condition for one of the outer turns of the ohmic heating coil. Although important, these loadings do not affect the wall and skin sizing. Thermal stresses must also be included in the detailed design stage.

Static Stress Analysis. For the static atmospheric loading, an analysis based on a thin shell of revolution produces membrane stresses (in the plane of the shell) acting in the toroidal and poloidal directions. The membrane stresses are compressive everywhere except on the inboard wall where the pressure causes hoop tension. The largest membrane stress is in the toroidal direction 
on the outer wall and is equal to $37 \mathrm{MPa}$ (5,400 psi). The analysis was performed for a three layer shell, with the middle layer representing the corrugations. In addition to membrane stresses a maximum bending stress of $52 \mathrm{MPa}(7,500 \mathrm{psi}$ ) occurs on the top and outboard conical sections in the poloidal direction. It is conservatively assumed throughout this analysis that the corrugations do not provide any structural support in the toroidal direction. Effects due to penetrations have not yet been included, but clearly the insertion of a port will require the addition of structural material in the surrounding area in order to compensate for material removed. Figure 4 shows a three-dimensional, first generation shell model being used in the more detailed analyses.

Dynamic Stress Analysis. As earlier described, a $1 \mathrm{~ms}, 5 \mathrm{MA}$ plasma current disruption causes maximum impulsive loads on the vessel of 6.1 and 3.4 atmospheres on the inner and oliter walls, respectively. The pressures are reached in about $1 \mathrm{~ms}$ then decay with time according to the $L / R$ time constant of the vessel. A dynamic analysis is in progress to evaluate the disruption stresses. Preliminary results indicate that a peak stress of approximately $220 \mathrm{MPa}$ (32 ksi) occurs at both the inner and outer walls.

Structural Stability. The spacing of the two skins is governed by the structural stability of the vessel owing to the combined static and dynamic loads. Prior to a detailed thin shell of revolution buckling analysis, an approximate value for the minimum buckling pressure can be obtained by treating the dee-shaped 


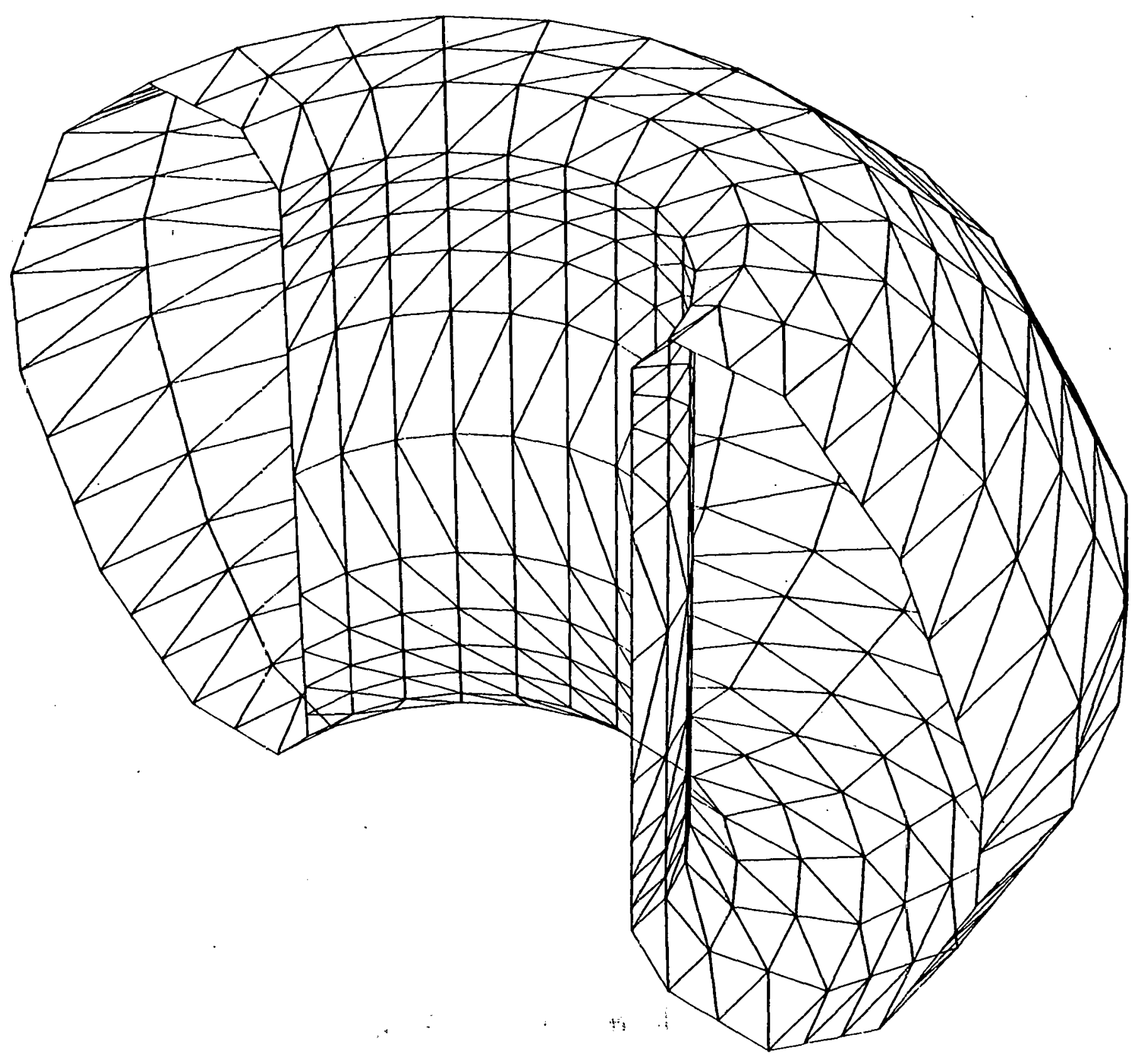

Fig. 4. 3-D finite element model of Big Dee vacuum vessel 
vessel as a circular torus whose outer surface approximates that of the dee vessel. For this analysis, the sandwich wall is substituted by a stiffness equivalent monocoque wall which has an elastic modulus of $3.6 \times 10^{6} \mathrm{psi}$ and a thickness of $1.6 \mathrm{in}$. (The stiffness of the corrugations is conservatively neglected.) The critical uniform external pressure is about 14 atmospheres. Although this model is a crude approximation, both in geometry and disruption load distribution, the margin of safety against buckling is adequate for preliminary feasibility analysis.

Thermal Analysis. Thermal analysis of the vacuum vessel encompasses several areas. During discharge cleaning, allowable gradients across the vessel must be determined to define gas cooling requirements. As the inner wall is hotter than the outer wall, restrained thermal growth results in thermal stresses. Analysis shows a $100^{\circ} \mathrm{C}$ differential to be acceptable.

Maximum gradients across the wall itself during plasma operation must also be determined to establish operating limits prior to augmenting the startup cooling system. Detail stress analysis results in a $144^{\circ} \mathrm{C}$ maximum allowable inside wall temperature during a plasma discharge. Thermal stresses are combined with vacuum and disruption loads to determine the above allowable.

\section{Vacuum System}

The vacuum pumping system for the Big Dee is presently in place on Doublet III. This system should be adequate to provide the required maximum internal pressure of $2 \times 10^{-8}$ Torr. 
The present system consists of four turbomolecular pumps and two cryopumps. Each turbopump has a nominal $\mathrm{H}_{2}$ pumping speed of $1,000 \ell / \mathrm{sec}$ and each cryopump $3,000 \mathrm{\ell} / \mathrm{sec}$.

The exhausts of the turbopumps are manifolded together and connected to one of three mechanical roots blower roughing pumps rated at $600 \mathrm{cfm}$. For roughing down the vessel, the turbopumps are bypassed and the mechanical pump is directly connected to the vessel via an isolation valve and $\mathrm{LN}_{2}$ cold trap.

The design task for Big Dee will involve adequate interfacing of the new vessel to the existing system. Provisions will be made for enhanced pumping access should it be required in the future. Pumping access will also be provided for the pumped limiter and the divertor discharges where getter pumps are proposed.

Vessel Insulation

To protect the F-coils from the high bakeout temperature, the entire vessel is covered with a thermal blanket, which will keep the F-coils below $80^{\circ} \mathrm{C}$ when the vessel is at $250^{\circ} \mathrm{C}$ during discharge cleaning.

\section{Vessel Cooling}

To maintain an allowable temperature gradient throughout the vacuum vessel during discharge cleaning and a given maximum temperature during normal operation, a phased cooling system is planned. At startup the vessel can be adequately cooled between discharges by either conductive/convective cooling as presently employed or by flowing gas in the wall corrugations to increase 
the cooling effectivity. Once rf heating is added in excess of approximately $50 \mathrm{MJ}$, the vessel inside wall temperature reaches its $144^{\circ} \mathrm{C}$ allowable. The peak temperatures and associated thermal stresses can be controlled by installing a water-cooled heat shield inside the vessel. Water cooling will also be required for adequate cooldown time.

\section{Acknowledgements}

This paper represents a brief overview of a great deal of effort by many people during the conceptual design phase of Big Dee and serves as an update of previous reports.[4,5] Special, acknowledgement is extended to John Wesley, Chairman of the Big Dee Design Task Force; John Rawls, who has been instrumental in establishing the Big Dee concept and project; Jim Luxon, who has been responsible for developing the physics design base; Fred Puhn, who directed the overall mechanical engineering effort; and Rémy Gallix, who has taken on the formidable task of vacuum vessel analysis and who has graciously agreed to present this invited paper in the author's absence. Many others have been involved and concerned with this endeavor and will continue as the design is completed and hardware brings ideas to reality. 


\section{References}

1. Burrell, K. H., et al., "Attainment of Reactor Level Volume Averaged Toroidal Beta in Doublet III," submitted for publication to Nucl. Fusion, September 1982, General Atomic Company Report GA-A16883, September 1982.

2. Miller, J. E., "Unique Design of Doublet and Big Dee Vacuum Vessels," 28th National Symposium for the American Vacuum

- Society, Anaheim, CA (1981), General Atomic Company Report GA-A16475, November 1981.

3. Luxon, J. L., General Atomic Company, private communication.

4. Rawls, J. M., et al., "A Design Study of a New Vacuum Vessel for Doublet III," General Atomic Company Report GA-A16143, October 1980 .

5. Davis, L. G., and J. M. Rawls, "Modification of Doublet III to a Large Dee Facility," 9th Symposium on Engr. Problems of Fusion Research, Chicago, IL (1981), General Atomic Company Report GA-A16507, October 1981. 


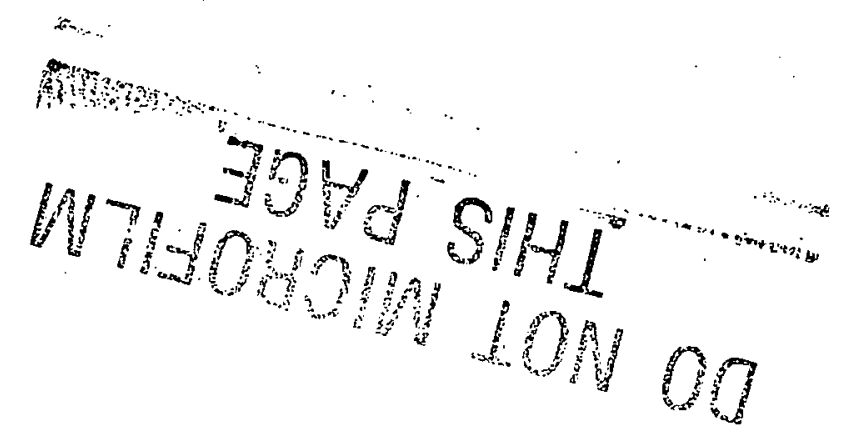

GA Technologies Inc.

SAN DIEGO; CALIFORNIA 92138 